\title{
PHOTOVOLTAIC SYSTEMS - TYPES OF INSTALLATIONS, MATERIALS, MONITORING AND MODELING - REVIEW
}

\author{
Angelika Anduła \\ Lodz University of Technology, Faculty of Process and Environmental Engineering \\ 213 Wolczanska St., 90-924 Lodz, Poland, angelika.andula@wp.pl \\ Dariusz Heim \\ Lodz University of Technology, Faculty of Process and Environmental Engineering \\ 213 Wolczanska St., 90-924 Lodz, Poland \\ (D) https://orcid.org/0000-0002-1036-5818
}

\begin{abstract}
Photovoltaic systems have become a common solution for, both small residential buildings as well as large service buildings. When buildings are being designed, it is important to focus on the aspect of the object's energy efficiency as lowering the energy consumption of a given facility is crucial. The article discusses the use of photovoltaic panels such as so-called BAPV (Building Applied Photovoltaics) and BIPV (Building Installed Photovoltaics) installations as well as photovoltaic thermal systems (PV/T), which generate both electricity and heat. The role of PV installation in so-called zero energy buildings and proposals for future research and solutions are also discussed.
\end{abstract}

\section{Keywords}

photovoltaic systems, BIPV, BAPV, PV/T, energy sources, modeling

\section{Introduction}

Photovoltaics is the field of science dealing with the production of electricity from solar radiation. The sun's rays falling on the surface of a photovoltaic cell gives rise to a photoelectric effect. As a result of this phenomenon, the positive and negative ions are separated and directed towards the opposite surfaces of the cell, thereby generating electrical voltage. In this way, photons falling on the surface of the cell cause a flow through the DC circuit. The electricity produced by the photovoltaic system is constant current, while the alternating current (AC) is being charged from the grid. In order to be able to supply electrical equipment in the home, a power inverter, also known simply as an inverter must be used. Its purpose is to convert direct current (DC) into alternating current. The inverter also provides information on the performance of the installation at a given moment or time. The parameters of the generated current are dependent on the insolation and the number of photovoltaic panels included in the entire installation. Therefore, the intensity of the current depends on the amount of sun, while the voltage and power of the installation depends on the number of connected panels (the more PV panels, the greater the installation's power).

PV solar panels are a versatile solution due to the possibility of assembly, both on buildings with flat or sloping roofs or on the facade of a building (a wide range of fasteners allows maximum use of available space), as well as on the surfaces around them. The panels are easily integrated with the building itself, so that a limited installation area around the building is not a problem. The most important is that they provide energy production from a renewable energy source (RES) "on site", which is also a great advantage [1]. This is an extremely important issue, especially in large urban agglomerations, where the demand for electricity is very great and space for large installations is relatively small [2].

The limitations encountered from the usage and depletion of fossil fuels has contributed to the need for taking action to reduce greenhouse gas emissions. An interesting aspect in this era of pressing need to use renewable energy sources are the so-called zero-emission buildings. These are buildings with almost zero energy demand. In order for such buildings to be created, technologies limiting energy consumption should be used and the potential of unconventional energy sources such as solar installations should be utilized [3].

\section{Methods}

1. Materials

Technological innovations have affected the photovoltaic panel market by introducing more and more new 
solutions. In addition, the growing number of producers and ensuing increase in competition has resulted in a gradual decrease in the prices of solar panels. As a result, interested parties can find financially viable modern solutions [4].

The three basic divisions of photovoltaic panels:

- monocrystalline panels - a single crystal cell is made of one crystal. As a result of technological processes in manufacturing, single silicon cylindrical crystals are obtained, which are then cut into thin polygonal plates that are used in panels. The two most important advantages of photovoltaic modules composed of monocrystalline cells are high efficiency (in the case of currently manufactured modules on an industrial scale is up to 25\%) and long life (at least 30 years). High efficiency is obtained because of precise, equal orientation of the crystal structure in one direction. Panels built of these links are black, although in the sunshine they appear navy blue,

- polycrystalline panels - consist of many silicon crystals. The efficiency of high-quality polycrystalline photovoltaic cells is not significantly lower than that of monocrystalline cells, the max. is $21 \%$ (average $12-14 \%)$. Due to their reasonable value for money, they are most often chosen by investors. Panels built of polycrystalline cells are blue,

- thin film panels - among this group can be distinguished amorphous silicon panels, CdTe panels as well as CIS and CIGS panels. The advantages of this group include low price, low weight (due to which they can easily be attached on the facades of buildings) and low susceptibility to high temperatures. However, these advantages tend to lower the efficiency of panels and raise costs of additional system devices (investment in a more expensive installation).
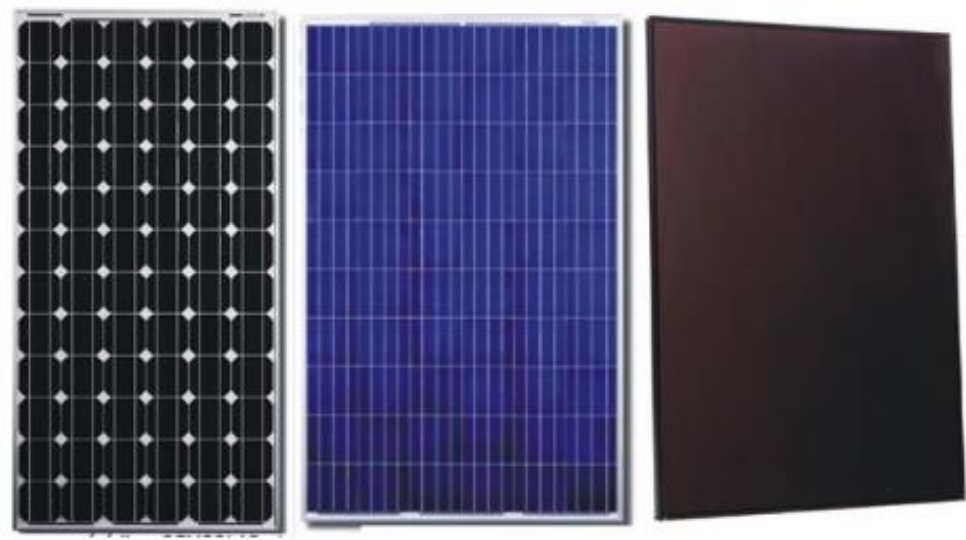

Fig. 1. Silicon solar cells with difference in structures of construction - monocrystalline, polycrystalline and amorphous. Source: [5]

The values of power output, specific energy yield, normalized power output as well as efficiency and performance ratio for monocrystalline and polycrystalline modules have been analyzed by Marzaei and Mohiabadi [6]. The test was conducted during 2014 in an outdoor environment in southeastern Iran. This site is characterized by semiarid climate conditions; hot and dry summer and relatively cold winter; the humidity values are generally below $25 \%$ and can reach $40 \%$ in cold months.

It was shown that due to the different light absorbing and thermal characteristics of each panel, the performance of monocrystalline module decreases with increasing monthly ambient temperature. The monthly average efficiency of a monocrystalline module showed a gradually decreasing trend in months with a higher ambient temperature, while the polycrystalline modules showed an inverse behavior [6].

As expected, the summer months of June and July appear to have the greatest amount of sunshine, which leads to the best specific energy, while for both modules, the least amount of specific energy is produced during the darkest winter months, November-February. This is shown in Fig. 2.

By comparing the results, it is also possible to observe that in non-summer months, the monocrystalline module had a significantly higher specific energy than the polycrystalline module, while during the summer months, this value for the polycrystalline module is higher [6]. 


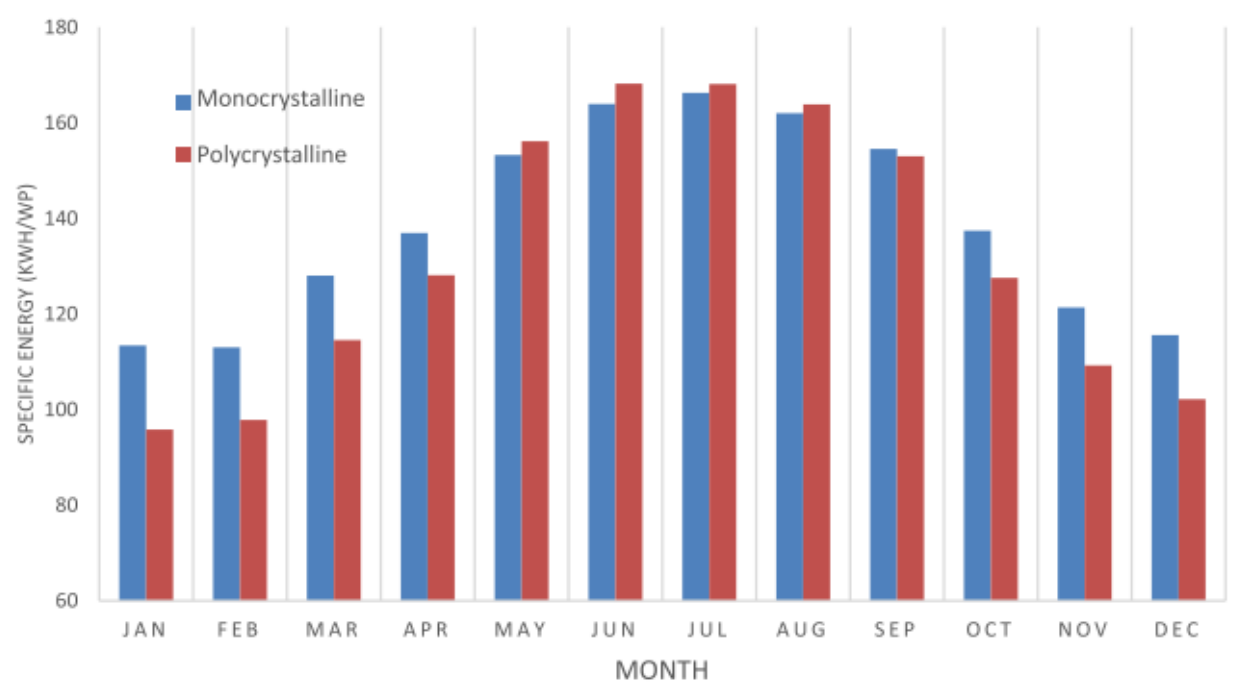

Fig. 2. Monthly total energy generated over the monitored period. Source: [6]

\section{Types of PV installations - BIPV, BAPV, PV/T}

PV (photovoltaics) systems are a new element in the design of building facades. Currently, two types of photovoltaic systems can be distinguished: BIPV (Building Integrated Photovoltaics) and BAPV (Building Attached Photovoltaics). The first are systems directly integrated with the building. The second consists in adding photovoltaic facades to the building surface using a separate assembly system.

The idea of BIPV is to use photovoltaic elements as a component of traditional building components serving, for example, as windows, roofing or other glass elements on the facade or roof. These installations are intended to perform the functions of the elements they replace, e.g. they constitute roofing in place of traditional materials, additionally they positively affect the external aesthetics of the building [7]. BIPV systems come in a variety of forms such as transparent, opaque and translucent modules, as well as a thin photovoltaic film. PV panels can be vertically mounted on the surface of the building wall, but also at an angle, for example, as a shading overhang. Installation is also possible on roofs (Fig. 3). It is worth noting that cells installed at an angle on the building's wall generate higher energy gains than in the case of horizontal or vertical installations, which results from a more favorable angle of incidence of solar radiation. The BIPV installation generates electricity, which can be used to power various receivers inside buildings, as well as emits heat, which arises during photothermal energy conversion of solar radiation. In addition, glass modules (semitransparent systems) partially transmit solar radiation to the rooms inside the building. By using cells as shading elements, the amount of radiation reaching rooms can be additionally adjusted to avoid overheating. BIPV installations are an interesting alternative in regard to high-rise buildings, for example offices located mostly in dense buildings of city centers. However, when considering this solution, it should be remembered that increasing the surface covered with panels reduces the surface of windows, and thus glazing, that is, the effective surface illuminating the interior of the building with daylight [8].

BAPV systems are the most frequently used systems. In the case of photovoltaic modules, the installation does not affect the transference of solar radiation, but it also generates electricity [9].

Compared with BAPV systems, BIPV systems are more expensive and can cause complications in structures such as difficulties in maintenance and mounting [9]. 


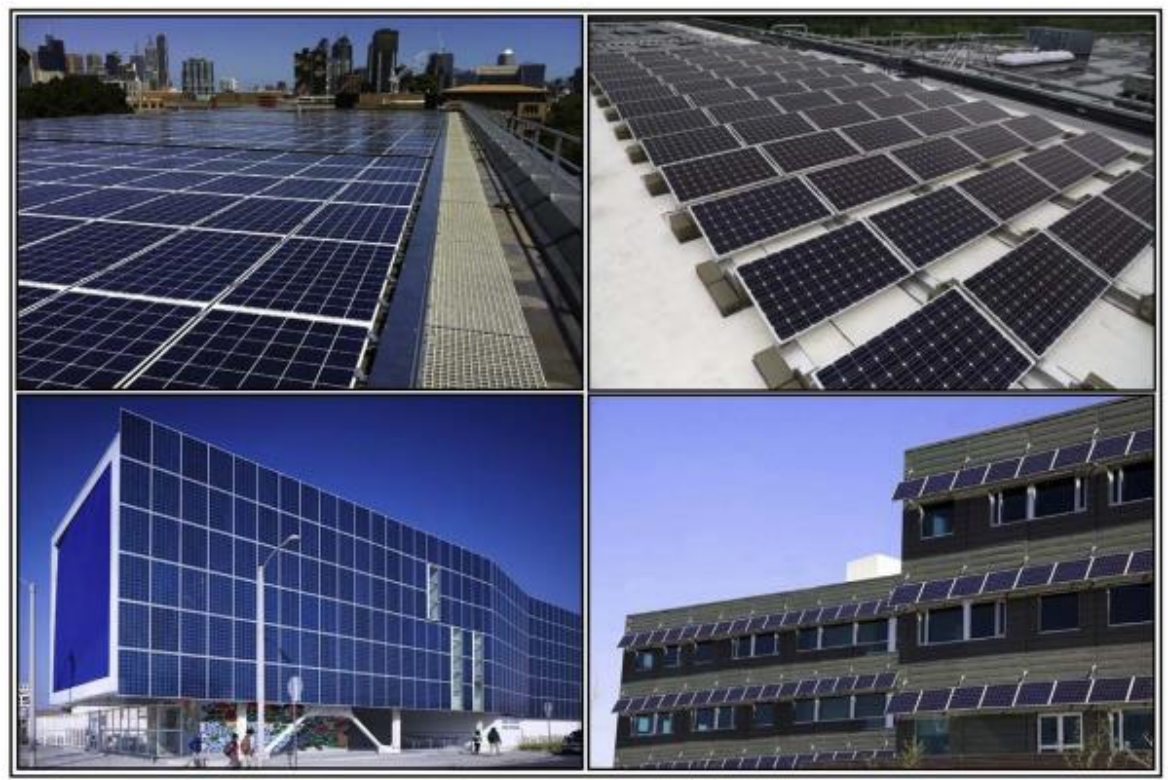

Fig. 3. Flat and tilted panel installation over building roofsand facades. Source: [10]

Photovoltaic-thermal (PV/T) systems are also worth noting. To improve the efficiency of traditional photovoltaic systems, hybrid photovoltaic and thermal collector systems have been developed. A photovoltaic-thermal system handles both the generation of electric power and collection of thermal energy simultaneously. Studies by Jia et al. and Sultan and Efzan [11- 12] presented that the applications and developments of PV/T systems defined the appropriate environmental conditions and applications for different kinds of this systems. A photovoltaic/thermal hybrid (PV/T) system is an integration of photovoltaic and solar thermal components. It consists of conventional thermal collectors with an absorber covered by a PV layer [13]. The PV modules produce electricity and simultaneously the absorbed thermal energy is transported away by the working fluids. As a result, the PV efficiency improves. The advantages of such systems include: using much less space (than installing two separate systems with PV and thermal collectors) more electricity and heat are produced; installation costs are lower than for two separate systems; using the PV/T system, the uniformity of architecture on the roofs can be maintained; the total energy efficiency of the PV/T collector is higher than that of conventional PV systems and conventional thermal collectors [11]. PV/T collectors can be classified into four basic types. For example, as Zondar and colleagues reported [14] there are sheet-and-tube PV/T collectors, channel PV/T collectors, free flow PV/T collectors and two-absorber PV/T collectors, as shown in Fig. 4.

(A)

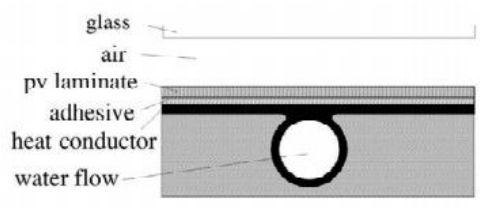

(C)

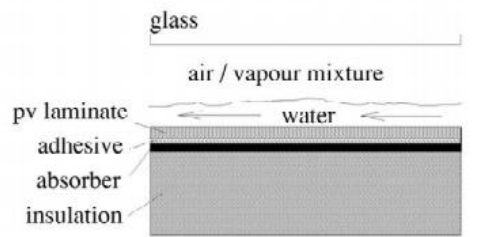

(B)

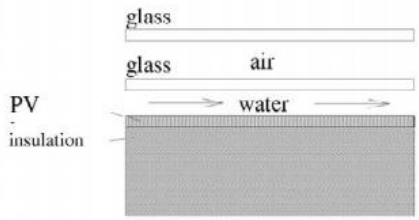

(D)

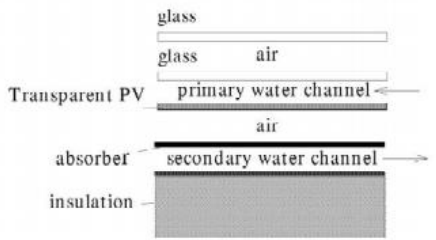

Fig. 4. Various collector concepts: (A) sheet-and-tube PVT, (B) channel PVT, (C) free flow PVT, (D) two-absorber PVT (insulated type). Source: [14] 


\section{Energy production from PV}

To achieve the highest possible energy gains generated by PV panels, at the design stage it is necessary to choose the best location of panels on a given object, taking into account the most favorable orientation, as well as the angle of inclination, so that sunlight will be at the highest level. Electricity in photovoltaic systems is produced only during the daytime, when the sun is out. The greatest energy gains can be counted primarily in the summer, as presented in the analysis by Anduła and Heim [15] in Fig. 5 and Fig. 2 where two types of PV panels were compared [6].

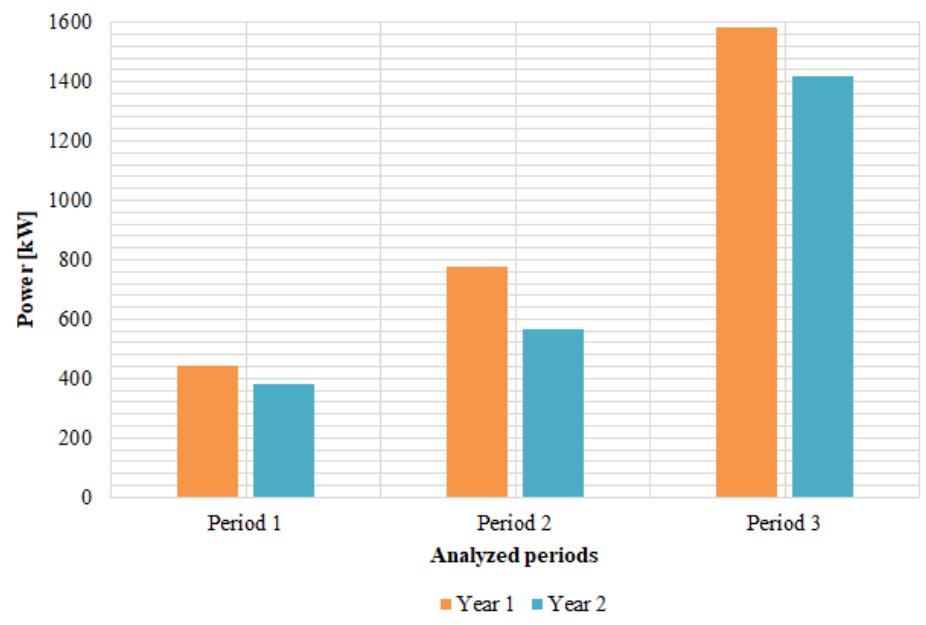

Fig. 5. Energy power generated by the PV façade. Source: [15]

A photovoltaic installation consists of eight PV panels, each panel at maximum capacity has a maximum power of $80 \mathrm{Wp}$. The study was conducted during three periods over the years 2015-2017: during the period of greatest demand for lighting, i.e. in the winter (October-February), during the period of average lighting demand, i.e. transition period (March-April and September) and in the summer, when the demand for room lighting is relatively small (May-August). The exact breakdown of the two analyzed years and periods is presented in Table 3.

Table 3. Characteristics of the analysed years and periods. Source: [15]

\begin{tabular}{|l|l|l|}
\hline & Year 1 & Year 2 \\
\hline $\mathbf{1}$ - Winter period & $10.2015-02.2016$ & $10.2016-02.2017$ \\
\hline $\mathbf{2}$ - Transition period & $03-04.2016,09.2016$ & $03-04.2017,09.2017$ \\
\hline $\mathbf{3}$ - Summer period & $05-08.2016$ & $05-08.2017$ \\
\hline
\end{tabular}

4. Monitoring and software

Choosing the right PV system depends on a number of factors. These include the visual effects one wishes to achieve, possibilities for adapting the facility to the assembly system, the amount of sun exposure a given facility receives, how effectively the installation is intended to be used in terms of energy production, as well as financial considerations. In addition, installed modules must be durable due to the difficulty and expense of replacement, for example on facades. It is therefore important to ensure, as far as possible, monitoring of the operation of the PV installation with the help of remote monitoring systems. The effectiveness of work in a specific situation for specific installations can be estimated by analyzing the profitability of investments using various types of calculators and types of software.

Wijeratne et al. [16] presented 23 solar PV design and management software and 4 smart phone or tablet applications for this purpose. The researchers analyzed their features against 15 key aspects of solar PV design and management. 
The analyzed online programs and applications included, among others: EasyPV, EasySolar, PVOutput and CalculationSolar.com. Also 14 problems related to the design and management of PV were identified such as lack of detailed meteorological data, lack of information for energy prices or information on local building regulations. The results showed that many programs or applications simply do not meet many aspects relevant to the design and management of photovoltaic installations. The platform shown in Fig. 6 was suggested to create effective and efficient design solutions in the field of photovoltaics and to provide the following features:

- a localized data repository, which will include weather information, building regulations, energy consumption of various building sectors, utility prices, construction and maintenance costs, contract types, financial modes, carbon emission factors and government incentive schemes,

- efficient 3D model creation of the physical environment,

- comparison of energy input and output,

- PV layout design optimisation,

- simulated installation process and impact analysis,

- monitoring and inspection modules with auto diagnosing function;

- PV system performance recording,

- sensitivity analysis and scenario based decision-providing support [15].

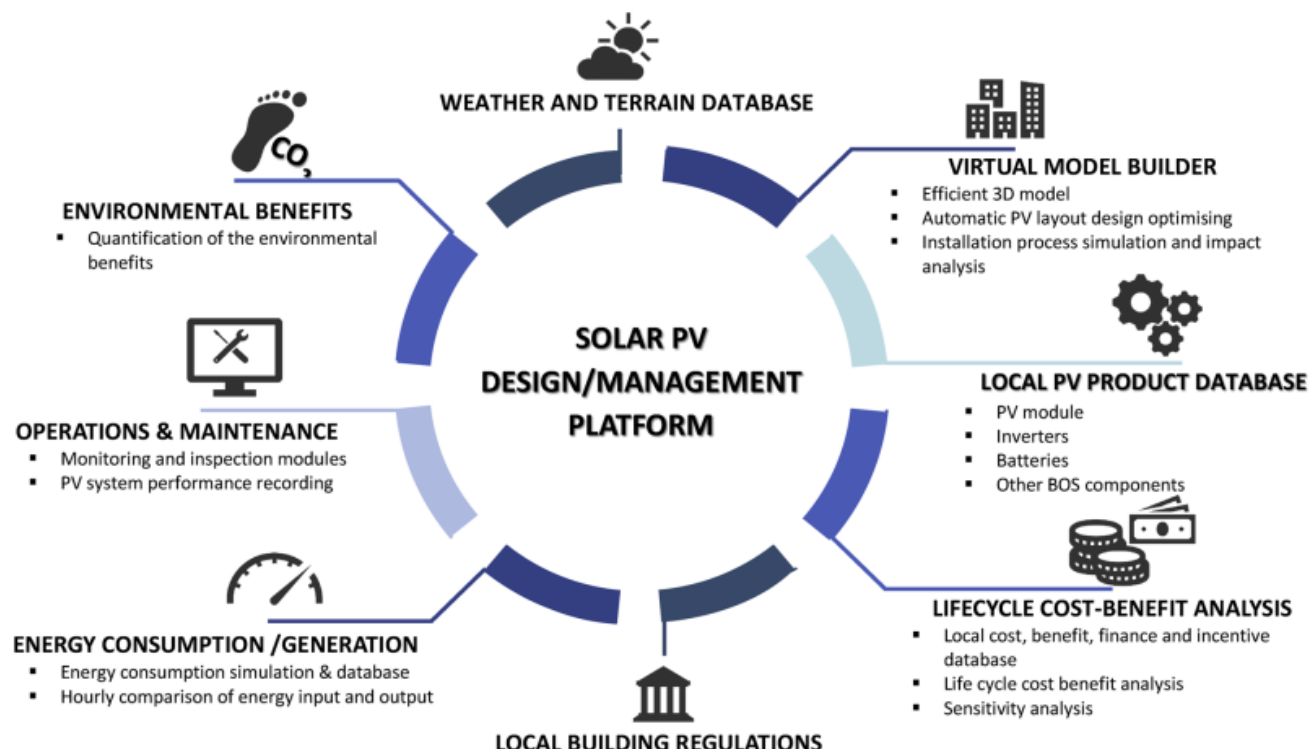

Fig. 6. Proposed platform for Solar design and management. Source: [16]

5. Mathematical models of photovoltaics and thermal panels.

An interesting solution is to create models of photovoltaic installations using computer software for objects with specific parameters. Such a model can help in the assessment of electricity production by a given installation [8, 17]. In addition, the successful implementation of PV systems requires an assessment of the potential of the system, which depends largely on exposure to solar radiation, which is different depending on the location [8, 18]. For example, Kovac et al. [17] described a model, which depicts the role of PV systems for small businesses. Single energy source models are quite accurate. Vulkan et al. [18] estimated the potential of electricity generation by BIPV installations in dense urban locations.

Castro et al. [19] presented a PV system model useful for steady state power flow tests of practical electrical networks. A characteristic feature of the proposed PV-based distributed energy resources (DER) power flow model is the consideration of three basic stages involved in solar energy conversion systems:

- PV arrays for the solar-to-electrical energy conversion,

- the DC boost converter along with the MPPT (maximum power point tracking) strategy,

The DC-to-AC power conversion by the VSC (voltage source converter) station enables the connection of the PV system to the $A C$ grid. 
A generalized model for distributed photovoltaic systems in power grids, i.e. generalized linearization of an $n$ bus AC network power grids containing $j$ distributed photovoltaic systems, which in turn are comprised of $i$ photovoltaic arrays each, is as follows [19]:

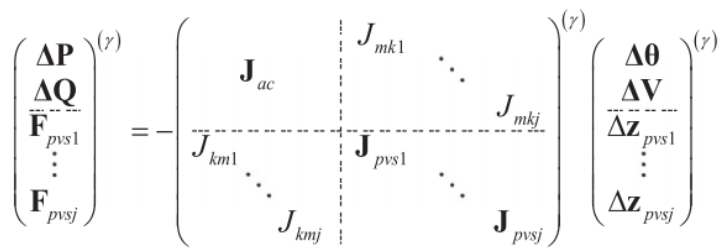

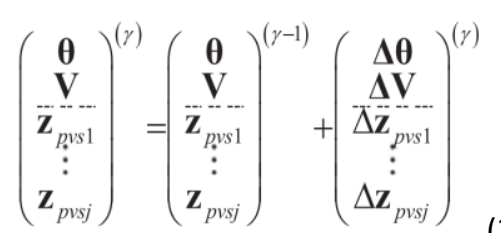

Matrix $J_{a c}$ stands for the conventional Jacobian matrix of the power grid. $\Delta \mathrm{P}, \Delta \mathrm{Q}$ are the nodal active and reactive mismatch powers, respectively. $\Delta \theta, \Delta \mathrm{V}$ signify the nodal phase angles and voltage magnitudes, respectively. Entries $F_{p v s}, J_{p v s}$ and $\Delta \mathbf{z}_{p v s}$ take the form of (3)-(5) for each of the distributed PV systems [19].

$F_{p v s}=-J_{p v s} \Delta z p v,(3)$

$\mathrm{F}_{\mathrm{pvs}}=\left[\Delta \mathrm{P}_{\mathrm{k}} \Delta \mathrm{Q}_{\mathrm{k}} \Delta \mathrm{P}_{0} \Delta \mathrm{Q}_{0} \Delta \mathrm{P}_{\mathrm{pv}} \Delta \mathrm{P}_{\text {loss }} \Delta \mathrm{l}_{\mathrm{opt}} \Delta \mathrm{E}_{\text {opt }}\right]^{\top},(4)$

$\Delta \mathrm{z}_{\mathrm{pvs}}=\left[\Delta \theta_{\mathrm{k}} \Delta \mathrm{m} \Delta \phi \Delta \mathrm{B}_{\mathrm{eq}} \Delta \alpha \Delta \mathrm{G}_{\mathrm{sw}} \Delta \mathrm{I}_{\mathrm{MPPT}} \Delta \mathrm{E}_{\mathrm{MPPT}}\right]^{\top},(5)$

The terms $J_{k m}$ contain the firstorder partial derivatives of the functions (6) with respect to the mth node of the AC system.

$\Delta P_{k}=-P_{k d c}-P_{d k}-P_{k}^{c a l},(6)$

The terms $J_{m k}$ accommodate the first-order partial derivatives of the active power balance of the mth AC system node with respect to the nodal phase angle $\theta \mathrm{k}$ bus related to the point of connection of the PV system. At the end of each iteration $(\gamma)$, the state variables of both the power network and the distributed PV systems are updated [19].

Das et al. [20] have developed a new thermal model considering the thermal contact resistances between different layers of a PV/T module along with solid contact resistances.

For one-dimensional heat conduction with uniform heat generation per unit area and incident radiation falling on the substance, the energy balance can be expressed in a simplified way by the formula, where $\mathrm{R}$ is thermal resistance, $\mathrm{T}_{\mathrm{a}}$ - ambient air temperature, and $\mathrm{G}_{\mathrm{T}}$ - solar radiation:

Slayer $\rho C_{p} \frac{d T}{d t}=\frac{\Delta T}{R^{\prime \prime}}+Q^{\prime \prime}$ generation $+h_{\text {equivalent }}\left(\mathrm{T}-\mathrm{T}_{\mathrm{a}}\right)+\mathrm{G}_{\mathrm{T}},(7)$

A portion of solar radiation incident on the front glass PV T is transmitted to PV layers, where then its part is absorbed by the PV cell. The expression $f_{\alpha_{c}} \tau_{g} G_{T}$ denotes the amount of solar radiation absorbed by PV cell layers. $\frac{T_{c-T g}}{R_{1^{\prime \prime}}}$ provides the conduction heat flux from the cells to the front glass and $\frac{T_{c-T_{g}}}{R_{2^{\prime}}}$ provides the conduction heat flux from the cells to the back absorbing plate. The variable $\frac{i^{2} R_{\text {internal }}}{A}$ represents the area averaged Ohmic loss and the expression $\eta_{c} f \alpha_{c} \tau_{g} G_{T}$ represents the electrical output per unit area of the PV/T module [20]. Using the formula (7) for the PV layer, the following equation was obtained:

$\frac{d T_{C}}{d t}=\frac{1}{\left(\rho C_{p}\right)_{a v}}\left[-\left(\frac{T_{c-T g}}{A R_{1^{\prime \prime}}}\right)-\left(\frac{T_{c-T_{a b}}}{A R_{2^{\prime \prime}}}\right)+\frac{i^{2} R_{\text {internal }}}{A}+f \alpha_{c} \tau_{g} \tau_{E V A} G_{T}(\mathrm{t})-\eta_{c} f \alpha_{c} \tau_{g} \tau_{E V A} G_{T}(\mathrm{t})\right],(8)$ 
For the PV cell layer the average specific heat capacity becomes module [20]:

$\left(\rho C_{p}\right)_{a v}=f\left(\rho C_{p}\right)_{P V}+(1-f)\left(\rho C_{p}\right)_{E V A},(9)$

The developed model can be applied under varied climatic conditions since it uses the ambient conditions as an input.

Interesting studies were conducted and described by Maadi et al. [21]. A coupled thermal-optical 3D model was developed, combining computational fluid dynamics and ray tracing to evaluate the performance of a glazed $\mathrm{PV} / \mathrm{T}$ module. The greenhouse effect in the simulation had a significant effect on thermal efficiency, but the electrical efficiency was not significantly altered by the greenhouse effect. The results indicated that increasing the tube number and bonding width have a significant effect on the temperature distribution of the PV cells, and performance of the PV/T module.

\section{Impact}

Solar installations are an ecological alternative to traditional energy sources whose negative impact on the environment is widely recognized. Thanks to solar installations the amount of consumption of raw materials such as coal can be reduced, which positively contributes to reducing emissions of pollutants into the environment, and consequently has a positive effect on people and the surrounding nature. It is a myth that the production of solar panels requires more power than they can produce during the entire period of their functioning. Solar panels have a lifetime of between 25 and 35 years. During this time, they are able to generate at least 10 times more energy than used for their production, and in countries with the highest saturation with this type of systems, this amount doubles.

Much of society remains convinced that solar power is still unprofitable and too expensive an investment. Of course, the actual result depends on the type of installation and the materials from which it will be made. This is discussed in detail in chapter 2 of the above work. Many state institutions aid citizens by offering various types of subsidies that make the cost of building installations much lower. In addition to economic concerns, many people are convinced that it is only profitable to build solar installations in countries where sunny days occur all year round. Such fears are not justified, as can be seen from many countries that invest in this technology where sunlight conditions are relatively similar to the United Kingdom. It should also be remembered that photovoltaic cells produce energy depending on the amount of sunlight delivered, and not depending on the ambient temperature. What's more, the panels work better at lower temperatures than at very high ambient temperatures (a decrease in power is associated with an increase in temperature), therefore, the amount of energy generated on a sunny winter day can be similar to the energy yield on a hot summer day. Low temperatures are beneficial for installations because the panels increase their voltage and energy yield.

Investing in PV installations is also beneficial for the economy. Many users, above all, those with on-grid installations (installations connected to the electricity grid) are not only consumers but also producers of electricity. Each photovoltaic micro installation can be connected to the network, thanks to which any surplus of produced energy can be discharged to the network, and then (depending on the regulations in force in a given country) the appropriate amount uploaded to the grid can then be downloaded when it is needed, which provides a huge benefit for both society and the state.

It should be mentioned that like all new technologies, PV installations also poses threats to people and the environment and work on improving their safety is an ongoing challenge for scientists. Standardization documents of European countries, as well as in the United States and Australia, draw attention to many threats, and display the correct ways of making photovoltaic installations and their protection. The small number of recorded accidents shows that the probability of a negative event occurring from a photovoltaic system is low, especially if the entire installation is designed correctly, made of good quality materials, has properly selected equipment and has been correctly maintained. Nevertheless, there are some potential threats posed by photovoltaic systems that have been noticed by various security experts in many countries. Many countries also pay attention to the level of safety service during maintenance of installations and in the event of random events related to fires of buildings on which solar panels are installed. Threats posed by a PV installation include fire hazard, a risk of electric shock (especially in the case of installers or system conservators) and a threat associated with damage to other electrical devices in buildings where the installation has been installed in the event of a possible failure. 
Solar installations are becoming an increasingly popular source of renewable energy. An important element that will allow for greater interest in solar systems in the future will certainly be the decline in the price of modules and the possibility of resale of produced electricity at even more favorable prices. Photovoltaic installation projects made in accordance with high standards and regulations will certainly significantly extend the lifetime of the investment. Correct installation and proper cable routing increase the efficiency of overvoltage and lightning protection. In addition, the use of lightning and surge protection systems will eliminate the risk of damage to photovoltaic installations that may arise because of lightning and power surges from power lines.

\section{Conclusions}

The article presents issues regarding the field of photovoltaics. The application of PV systems depends highly on climatic conditions. It is common that PV systems can transfer solar energy into electricity in summer, however in winter, additional energy input is needed to satisfy the supply of energy. It should be remembered that the largest production of electricity from photovoltaic panels takes place during the day, when solar energy is in abundance. In order not to lose the energy produced, the best solution is to use energy storage systems.

Future studies should examine materials from which it is possible to produce technologically better PV facades to expand the market with new materials meeting specific needs. As the demand for renewable energy sources is high, the market potential of PV provides a solution that will help solve environmental problems (solar rays are free, non-polluting and is an inexhaustible source) and introduce new technologies to the global market. To make this happen, a larger investment in accurate computer programs is needed, thanks to which it will be possible to run accurate simulations that provide modeling and designing of modern systems that meet specific needs.

\section{Conflict of interests}

There are no conflicts to declare.

\section{Acknowledgments}

This research has not been supported by any external funding.

\section{References}

[1] D. Powell, I. Hischier, P. Jayathissa, B. Svetozarevic, A. Schlüter, A reflective adaptive solar façade for multibuilding energy and comfort management, Energy \& Buildings 177 (2018) 303-315.

[2] S. Freitas, C. Reinhart, M.C. Brito, Minimizing storage needs for large scale photovoltaics in the urban environment, Solar Energy 159 (2018) 375-389.

[3] R. Vanaga, A. Blumberga, R. Freimanis, T. Mols, D. Blumberga, Solar facade module for nearly zero energy building, Energy 157 (2018) 1025-1034.

[4] R. Venkateswari, S. Sreejith, Factors influencing the efficiency of photovoltaic system, Renewable and Sustainable Energy Reviews 101(2018) 376-394.

[5] Katalog produktów fotowoltaicznych 2015/16, Energy Partners.

[6] M. Mirzaei, M. Z. Mohiabadi, A comparative analysis of long-term field test of monocrystalline and polycrystalline PV power generation in semi-arid climate conditions, Energy for Sustainable Development 38 (2019) 93-101.

[7] M.J. Sorgato, K. Schneider, R. Rüther, Technical and economic evaluation of thin-film CdTe building integrated photovoltaics (BIPV) replacing façade and rooftop materials in office buildings in a warm and sunny climate, Renewable Energy 118 (2018) 84-98.

[8] A. Bellazzi, L. Belussi, I. Meroni, Estimation of the performence of a BIPV facade in working conditions through real monitoring and simulation, 73rd Conference of the Italian Thermal Machines Engineering Association (ATI 2018), 12-14 September 2018, Pisa, Italy, Energy Procedia 148 (2018) 479-486.

[9] K. Irshad, K. Habib, R. Saidur, M.W. Kareem, B.B. Saha, Study of thermoelectric and photovoltaic facade system for energy efficient building development: A review, Journal of Cleaner Production 209 (2019) 1376-1395.

[10] Y. Li, Ch. Liu 2018, Techno-economic analysis for constructing solar photovoltaic projects on building envelopes, Building and Environment 127 (2018) 37-46.

[11] Y. Jia, G. Alva, G. Fang, Development and applications of photovoltaic-thermal systems: A review, Renewable and Sustainable Energy Reviews 102 (2018) 249-265.

[12] S.M. Sultan, M.N.E. Efzan, Review on recent Photovoltaic/Thermal (PV/T) technology advances and applications, Solar Energy 173 (2018) 939-954. 
[13] F. Calise, M. Dentice d'Accadia, A. Palombo, L. Vanoli, Dynamic simulation of a novel high-temperature solar trigeneration system based on concentrating photovoltaic/thermal collectors, Energy 61 (2013) 72-86.

[14] H.A Zondag, D.W de Vries, W.G.J. van Helden, R.J.C. van Zolingen, A.A. van Steenhoven, The yield of different combined PV-thermal collector designs, Solar Energy 74 (2003) 253-269.

[15] A. Anduła, D. Heim, Productivity of PV facades in characteristic periods with different energy demand for lighting, Acta Innovations, no. 30, January 2019, 16-23, ISSN 2300-5599.

[16] W.M.P.U. Wijeratne, R.J. Yang, E. Too, R. Wakefield, Design and development of distributed solar PV systems: Do the current tools work?, Sustainable Cities and Society 45 (2019) 553-578.

[17] M. Kovac, G. Stegnar, F. Al-Mansour, S. Merse, A. Pecjak, Assessing solar potential and battery instalment for self-sufficient buildings with simplified model, Energy 173 (2019) 1182-1195.

[18] A. Vulkan, I. Kloog, M. Dorman, E. Erell, Modeling the potential for PV installation in residential buildings in dense urban areas, Energy \& Buildings 169 (2018) 97-109.

[19] L. M. Castro, J.J. Rodriguez-Rodriguez, C. Martin-del-Campo, Modelling od PV systems as distributed energy resources for steady-state power flow studies, Electrical Power and Energy Systems 115 (2020) 1505505.

[20] D. Das, P. Kalita, A. Dewan, S.Tanweer, Development of a novel thermal model for a PV/T collector and its experimental analysis, Solar Energy 188 (2019) 631-643.

[21] S. R. Maadi, M. Khatibi, E. Ebrahimnia-Bajestan, D. Wood, Coupled thermal-optical numerical modeling of $\mathrm{PV} / \mathrm{T}$ module - Combining CFD approach and two-band radiation DO model, Energy Conversion and Management 198 (2019) 111781. 